\title{
Learning, adaptation, and the complexity of human and natural interactions in the ocean
}

\author{
James Wilson ${ }^{1}$
}

ABSTRACT. Here, I explore the system-level consequences of learning and adaptation among fish and fishers. The fundamental idea is that the cost of acquiring the knowledge needed to resolve uncertainty is the principal driver of social and spatial organization. This cost limits agents' actions and leads them to prefer relatively persistent associations with familiar agents and places. When all agents act in this way, the regularity and self-reinforcing nature of familiarity leads to the emergence of a self-organized system. Systems like this are characterized by diverse, place-based, and relatively durable groups, groups of groups, and rough hierarchical structure. This occurs in both the natural and human parts of the system. The costs of resolving uncertainty also determine the interactions of fish and fishers. The uncertainty of search leads fishers preferentially to target older fish and aggregations of fish. These are the repositories and mechanisms for the replication of the knowledge needed for self-organization. The loss of this information selectively, but unintentionally, disrupts the behavioral regularity that organizes the natural system, leading eventually to its disorganization. From this theoretical perspective, sustainable fishing requires conservation of the knowledge in DNA and memory because this is the fundamental basis for the self-organization of the natural system. Collective action is also subject to the costs of resolving uncertainty. In complex systems, these costs are minimized at the local level in the system, where the most direct, but not the only, feedback occurs. This implies the need for multiscale governance with an emphasis on collective learning through localized science and user participation. Finally, the complexity of ecosystem interactions argues for qualitative harvesting rules governing how, when, and where fishing takes place. These rules are most likely to generate a persistent signal and rapid learning, but only when combined with effective governance.

Key Words: adaptation; bounded rationality; collective action; complex adaptive systems; feedback; fisheries management; information costs; inheritance; learning; overfishing; parametric rules; place-based behavior; rule-based behavior; self-organization; sustainability; uncertainty

\section{INTRODUCTION}

Evolution is accorded a central role in our understanding of natural systems; learning and the growth of knowledge are clearly important in human social systems. Nevertheless, analytical approaches to living systems are dominated by analogies with physical systems; there is no evolution or learning. The behavior of both natural and human agents is imagined to be fixed, except for the adaptive possibilities specified by the investigator. For example, a simple supply-and-demand model in economics carefully specifies the (price) conditional behavior of buyers and sellers; behavioral possibilities not foreseen by the modeler are not included, as if the modeler were fully knowledgeable of all possible outcomes in the market. Similarly, in models of natural populations, the dynamics are usually conceived as if there were (stochastically) stable functional relationships between, for example, reproducing adults and the numbers of subsequent offspring. The great advantage of thinking about living systems without regard to learning and adaptation is that it opens the door for the use of mathematics and statistical mechanics, i.e., the wellproven analytical tools of the physical sciences. However, it does tend to suppress curiosity about the effects of learning and adaptation.

An alternative way to think about living systems is as complex and adaptive. This perspective focuses on how inheritance and memory mold individual behavior and lead to the emergence of self-organized systems. The basic idea traces back to the physical sciences: the second law of thermodynamics argues that all matter is headed to a state of complete disorder or entropy. The creation of new order such as occurs in living systems requires energy and information; the important role of information is to guide the actions of agents in a way that channels energy into regular patterns (Maxwell 2001). Here, I explore the way both fish and fishers use selectively retained information to learn and adapt in ways that lead to both the organization and disorganization of the human and natural systems in the ocean. I argue that the costs of resolving uncertainty largely determine the interactions of agents with other agents and with particular places, and that this is the principal driver of system organization. The perspective is explicitly evolutionary and addresses both natural and human activities. It differs significantly from the perspective of modern fisheries science, leads to modeling with computational rather than mathematical approaches, and raises one's curiosity about the effects of learning and adaptation.

Modern fisheries science began after World War II in an era when mathematics and statistical mechanics had produced impressive advances in understanding the physical world (Weaver 1948). In these circumstances, it was reasonable to explore the idea that the factors affecting the abundance of fish might be understood through the application of theory and methods similar to those used for physical systems. Emerging from these explorations was the basic proposition that the complex temporal and spatial interactions of ecosystems could be ignored in favor of a simpler hypothesis about the dynamics of individual population abundance, i.e., the stock-recruitment relationship (Ricker 1954,

${ }^{1}$ University of Maine, USA 
Beverton and Holt 1957). Each population was assumed to be composed of large numbers of identical, nonadaptive agents. Changes in the population's abundance were assumed to be a density-dependent function of the size of its spawning biomass and the carrying capacity of its environment. From this relation, it was logical to infer that the population's spawning biomass could be manipulated through controled fishing in a way that would lead to a maximum sustainable yield (MSY).

Also strongly influenced by advances in the physical sciences, economists provided a complementary theory of fisheries built on the stock-recruitment idea. It explained the conditions under which profit-maximizing, homogeneous, human agents might fish at a rate exceeding the replenishment rate for each natural population (Gordon 1954). Importantly, it suggested institutional arrangements such as limited entry and catch shares designed to ameliorate overfishing while simultaneously maximizing economic yield.

This combined biological and economic theory, referred to here as the standard model, promised a rigorous scientific way to achieve sustainable ocean fisheries. It is an immensely influential concept that has been overwhelmingly adopted as the principal scientific and political rationale for national and international natural resource management regimes (Finley 2011). Most fisheries scientists and managers believe that maintaining spawning stock biomass at a level consistent with MSY should be their principal goal; the idea is firmly embedded in the public consciousness and in the many legal frameworks that guide fisheries management.

Unfortunately, despite research carried out now for $>50$ years, evidence for regular stock-recruitment relationships is weak, and the ability to manipulate the abundance and yield of fish populations has proved limited (Beverton 1998, Ulltang 1998, Longhurst 2010, Schindler and Hilborn 2015). These considerations, joined with the expansion of intensive harvesting across the globe (Myers and Worm 2003, Sethi et al. 2010), the marked declines in average trophic level in most fisheries (Pauly et al. 1998), the extensive depletions of once-abundant stocks (Pikitch et al. 2004), the long-lasting extirpations of many local stocks (Ames 2004, Rose 2005), and the widespread atrophy of local fishing communities, income, and employment (Charles 2001), have diminished the initial optimism accompanying the standard theory more than a bit.

These anomalies do not disprove the standard model, but they suggest the need for an alternative theoretical and practical management framework that might lead to a better understanding of the way human and natural agents interact. In fact, fisheries scientists and managers have responded to these deficiencies with a broad set of analytical methods and regulatory measures. Many of these responses are intended as refinements or extensions of the standard model, e.g., precautionary quotas, biological reference points, catch shares, limited entry, and proxy measures for MSY (Longhurst 2010). A variety of other approaches depart from the standard theory, usually relying on an eclectic blend of ecological and social theory, for example, the variations on closed areas and reserves (Levin and Lubchenco 2008), the widespread consensus on the need for ecosystem-based management (McLeod and Leslie 2009), territorial use rights (Christy 1982), and data-poor management (Ames 2010).
The perspective outlined here is consistent with most of these eclectic alternatives; it draws from a theoretical foundation that is fundamentally different from the standard model, relying heavily on the theory of complex adaptive systems (Beinhocker 2007, Levin et al. 2013, Holland 2014). However, it modifies that theory's usual perspective to focus on how human and natural agents adapt to the costs of resolving the uncertainty present in the very large number of signals they receive about their environments. Consideration of these information costs offers a compelling way to understand the emerging social, spatial, and trophic organization, and disorganization, of the combined human and natural systems. Attention to information costs also highlights the scale and kinds of feedback available in a complex system, which is helpful for a practical understanding of collective learning and adaptation.

Briefly, my argument here is this: The actions of both natural and human agents are assumed to be constrained by limited time, energy, and experience-based and inherited knowledge. In the language of economics, agents' abilities to act in a fully rational fashion is severely bounded. To survive, grow, and reproduce, both fish and fishers carefully expend their existing resources to assure a continuing flow of new energy and knowledge. These acquisitions are uncertain and costly, leading agents to seek relationships with other familiar agents and places for which the outcome of their actions is relatively certain. The benefits of familiarity are self-reinforcing (up to a point) and lead to persistent groups in persistent locations. When all agents act in this way, their individual actions lead to the emergence of regularity and order in the entire system.

The principal policy conjecture is that fishing unintentionally disrupts this order. It selectively targets the repositories and mechanisms for the intergenerational transfer of the information required for regular, especially place-based, behavior in the natural system and, consequently, leads to the erosion of its organization. Humans respond to this erosion by moving on to other parts of the system, increasing the erosion still more. Consequently, from this perspective, sustainable fisheries require the deliberate conservation of the information in DNA and social memory because this is the fundamental basis for the selforganization of the natural system.

I begin with a verbal model of the way uncertainty and costly information shape agent learning and adaptation and lead to the emergence of self-organized structure. The logical implications are described in the context of fisheries, emphasizing the differences in how complex self-organization emerges in both natural and human systems. I then explore the patterns that develop when two evolutionary systems, one slow and one fast, one natural and one human, intersect. The main idea is that rapid human adaptation combined with selective fishing patterns leads to the disorganization of the natural system. I then follow with a discussion of collective action for sustainable fisheries, drawing comparisons with the standard theory. The main point is that sustainable collective action requires a framework that enhances collective learning. This will require changes in the focal scale of science and governance and a shift to an emphasis on qualitative fishing rules. Finally, I summarize the entire argument.

Overall, I present an out-of-the-ordinary theory of system organization and dynamics. I attempt to conflate the connection 
between information, energy, and order with the dynamics of social and natural systems. For these reasons, the work is best read as an extended hypothesis by an economist venturing far outside the usual bounds of his field.

\section{COMPLEX ADAPTIVE FISHERIES}

\section{Adaptive agents}

"Complex adaptive systems [...] are composed of elements, called agents, that learn or adapt in response to interactions with other agents" (Holland 2014:24). Agents might be human, fish, or any self-interested entity capable of making choices or evolving to be better adapted to its environment.

\section{Information and rules}

It is assumed here that the actions agents choose to take depend on two forms of information:

1. A continuous flood of ephemeral information, or signals, about the state of the agent's environment, and

2. A relatively small stock of selectively retained and fairly durable information, i.e., knowledge, held by each agent as a result of its own experience, its communications with other agents, and its inheritance. This knowledge is held in DNA and memory and includes knowledge about the kinds of environmental signals that are likely to be relevant to the agent's circumstances.

The information each agent retains is held in a large set of behavioral rules, or heuristics, that reflect the agent's unique inheritance and experience (Holland 2012, 2014). The information in rules takes the form, "IF these relevant circumstance AND this action THEN this result." In other words, each rule informs the agent of previous outcomes of particular actions in particular circumstances and the likely outcome of similar actions in similar circumstances. The knowledge contained in these rules is mundane but useful, e.g., "orange fish produce a nasty shock when eaten." Changes in both inherited and learned rules are considered the evolutionary product of either genetic or learning processes. Thus, in the instance of learning, as an agent gains experience, its learned rules change and the agent adapts. It selectively builds and emphasizes new rules that predict the outcome of its actions well while at the same time passing over and discarding rules that do not. The continuous repetition of this learning algorithm, even though imperfect, generally leads to an increase in the agent's fitness. Similar logic, of course, applies to populations and inheritance (Fig. 1).

Individuals acquire rules from a variety of sources: from their own experiences, from inheritance, from the observation of others, and from institutions that encode collective experience. The rate at which a rule can change depends on the process by which the rule was developed (Andersen et al. 2015). Changes in the inherited rules contained in DNA tend to be slow and multigenerational; collective rules, i.e., the memory embedded in institutions and culture, change much faster; experience-based rules that individuals develop for their own use or copy from others are capable of rapid change (Mayfield 2013). This mix of fast and slow rates is important to the coupled dynamics of human and natural systems, as I elaborate later.
Fig. 1. Learning and adaptation can be modeled using rulebased computational methods, not equations or a conventional agent-based model. The basic structure of an evolutionary model is similar to an agent-based model, but agents learn from experience and change their behavioral rules in response. Learning takes place through selection and replication with variation, as in any evolutionary process. The computational equivalent of mutation and crossover gives agents the ability to generalize from their experience and to invent novel behaviors or rules, i.e., to adapt. Holland $(1975,2014)$ is credited with the initial development of evolutionary computation; Mayfield (2013) provides a good description of evolution as a computational problem. Urbanowicz and Moore (2009) provide a thorough introduction to, and review of, learning classifier systems, which is one common approach to evolutionary modeling. For a fisheries example of a learning classifier system, see Wilson et al. (2013b).

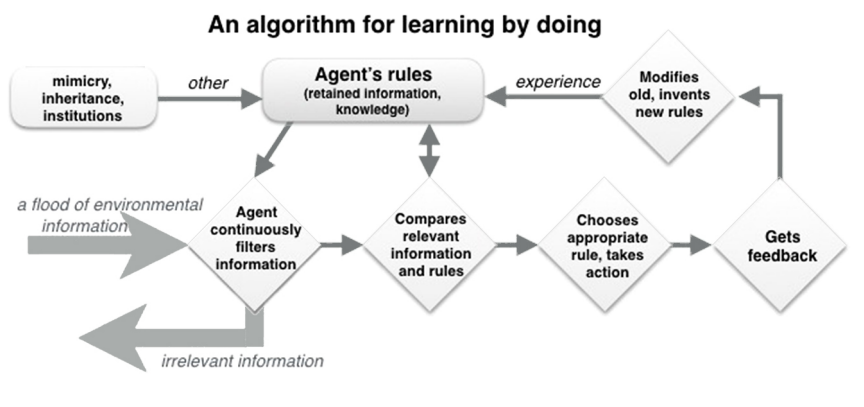

Capabilities for self-organization

The ability of living agents to learn and adapt is the basis for the emergence of complex self-organized structure (Mayfield 2013, Holland 2014). Holland (2014) emphasizes three cognitive abilities that are central to self-organization.

1. Building blocks: Agents are able to build on their experience using behaviors (or combined or modified forms of previously acquired behaviors) that work well in one setting to refine their adaptation in another similar setting.

2. Tagging: Agents are able to identify and discriminate among the regularities in their environment. Tagging allows agents to identify predator and prey, friend and foe, to build durable relationships, to form groups, and to recognize distinct places and persistent natural and social patterns.

3. Internal models: Based on their inheritance and learning, agents construct a set of imperfect, usually implicit, conditional expectations about the likely outcome of alternative actions (including searching for new information) and so are able to choose appropriately selfinterested actions. The entire set of each agent's rules encapsulates its knowledge of its environment and can be considered an imperfect, continuously evolving mental model of that environment. 


\section{Groups, feedback, and costly information}

\section{Groups are the building blocks of self-organization} Agents in complex systems form persistent relationships focused on a small number of other agents and restricted parts of the physical environment because the advantages of being a member of a group are usually great. For example, fish in a school are better able to avoid predators, find food, and reproduce. Groups of fishers are better able to search out fish, usually have better access to markets, and can acquire new technology more rapidly. When all agents seek out these advantages, they self-organize into systems of nearly independent, reasonably durable aggregations, e.g., schools of fish, gangs of fishers, pods of whales, cliques of teenagers, families, companies, and communities.

Simon (1962, 2002) calls this kind of organization "nearly decomposed;" Levin (1998) refers to it as "modular;" Ostrom (2000) calls it "polycentric." They all argue that it facilitates adaptation and rapid evolution, and as a result, it is close to ubiquitous in living systems, i.e., in ecosystems and social and economic systems. Similar observations about this kind of organization appear frequently in the economics literature (see Knight 1921, Coase 1937, Hayek 1945, Arrow 1962, Akerlof 1970, Williamson 1975, North 2005), and there are entire disciplines, i.e., anthropology, sociology, political science, ecology, and sociobiology, focused on the behavior of groups. Xie et al. (2016) provide an interesting parallel in neuroscience, and Thompson (2017) outlines equally interesting parallels in music, fashion, industrial design, and other cultural areas. I contend that information costs are implicit in all these literatures and that making these costs explicit leads to a general understanding of organization and dynamics that spans living systems.

From an information-cost perspective, members of a group obtain an advantage from the information economies that groups create. Agents have limited time and resources for the acquisition, processing, and use of information and can be easily overwhelmed by the vast amounts of information they encounter. To survive, they must simplify. They must learn who and what to pay attention to and who and what to ignore; they must learn what actions are likely to pay off without having to explore the multitude of usually fruitless and often dangerous possibilities open to them. To economize on these costs, both natural and human agents focus their actions and communications on familiar circumstances. Familiarity gives a sense of context; this leads to more accurate and meaningful observations, more refined adaptation, and consequently, to greater fitness (McCay 2002). Even when searching for new knowledge, agents proceed along paths that their experience suggests are likely to yield valuable outcomes. The value of familiar circumstances leads agents repeatedly to choose to act in those familiar circumstances, leading to still greater familiarity and more certain outcomes. This positive feedback is the source of the durable associations that are the foundation of selforganization.

Explained from a slightly different perspective, familiar circumstances mean that agents can base their actions on useful, experience-based knowledge that is far more likely to further their fitness than random actions in an unknown environment. This greatly reduces uncertainty, increasing the likelihood that the agents' actions will lead to favorable outcomes. In the language of Shannon's (1948, as cited in Mitchell 2009) information theory, agents attempt to minimize surprise. In a similar vein, Ostrom (1990) and North (2005) associate the deliberate creation of more predictable organization, i.e., institutions, with the creation of greater certainty. The difference between the arguments of North and Ostrom and mine is that my argument emphasizes selforganizing, not collectively deliberate, processes.

Groups enable inheritance and memory and vice versa

Membership in a group allows agents to take better advantage of the large information economies possible through inheritance and memory. In turn, inheritance and memory are not functional information mechanisms if they do not operate within the confined circumstances of a group. This mutual enablement is a critical aspect of self-organization that is not, to my knowledge, apparent in the literature. The argument supporting this contention is based on the idea of learning by doing (Arrow 1962, Holland 2014). The cognitive abilities of agents differ greatly, but all agents (species) have limited cognitive capacity. The scarcity of this capacity means that agents have to make the most of their capabilities. Groups are necessary, therefore, because they create a relatively restricted and stable environment that allows a limited cognitive capacity to be employed effectively. Communications among agents and encounters with places inhabited by the group are relatively frequent. As a result, individual agents can acquire repeated experience in similar circumstances, and from those experiences, construct a statistically tractable memory (or in the instance of a population, inheritance), even with a limited ability to record and recall their experience. This gives agents the ability to extrapolate from experience, to anticipate the outcome of various possible actions, and consequently, to adapt at a more rapid pace than might be possible in a less regular environment (Simon 2002).

The kinds of groups that form depend on the cognitive capacities of the relevant agents. Among fish, for example, the formation of groups is largely a function of their apparently limited cognitive capacity and their restricted range of communication. For that reason, groups tend to have a limited spatial extent and size. For an individual herring, for example, the cost of communication beyond a very small radius is very large; curiosity carries a potentially high penalty. Thus, the individuals in a school of herring are not drawn randomly from all of the herring in the world, but from fish that are close to one another. At the same time, herring appear to have little to say to one another beyond the extremely local signals necessary for swarming, so even with a limited cognitive capacity, they can form very large groups. Information costs and organization play out differently for fish with different capabilities, but because of the generally restricted ability to communicate, the organization of fish is relatively localized. Among humans, in contrast, widespread, relatively lowcost communication means that localization is much more a function of the networks to which individuals belong (Granovetter 1973, Watts 2003). Fishers can learn from and imitate other fishers hundreds of kilometers away, but rarely learn from cosmeticians or lawyers, or academics who might live next door, and vice versa (Wilson 1990, Wilson et al. 2013a, Barnes et al. 2017).

There are four sources of information economies: (1) knowledge acquired through biological inheritance; (2) knowledge an individual acquires through its own experience-based learning; 
(3) socially derived knowledge an individual gains through observation of, or communication with, other agents; and (4) collective knowledge that is contained in formal and informal institutions, i.e., customs, norms, and laws. The first three sources are individual based in that they are not dependent on deliberate collective mechanisms. They are the source of the information economies that drive self-organization.

Inheritance: Inheritance is the most persistent and ubiquitous way to economize on the acquisition of knowledge. DNA is a repository that provides agents with behavioral rules encapsulating millennia of experience. Among ocean animals, organizational patterns derived from inherited knowledge are well illustrated in the many species that do not seem to engage in social learning. Invertebrates such as zooplankton, shellfish, lobster, and crabs are found in patchy groups, but the behavioral rules that lead to their aggregations do not appear to be based on social mechanisms such as imitation. Instead, they appear to be governed by simple, inherited rules that lead to a generalized response to environmental conditions, e.g., "if there is no food, keep moving" or "avoid big fish" (Giske et al. 1998, 2013). Aggregations of animals operating only or principally with these kinds of nonsocial rules are like windrows on the surface of the sea.

Individual experience: Individual experience strongly complements the general knowledge acquired through inheritance. For example, inherited knowledge about avoiding bigger fish is important, but equally important is knowing from experience that a very big fish lives in a nearby cave. Similarly, for a fisher, the general knowledge required to operate a bottom trawl is exceedingly important and applicable in many different environments, but in a complex environment, knowing the particular local places that fish might be caught with the trawl is the difference between success and failure. In other words, individual learning allows an agent to combine general, broadly available knowledge with specific local knowledge to enhance the agent's ability to adapt to its local environment.

Social learning: Social learning occurs when individuals mimic or otherwise acquire the experience, i.e., the behavioral rules, of similar agents. It is a quick and economical way to benefit from the experience of others. Among humans, the information economies of social learning are staggeringly obvious, leading us to invest large sums in educating and socializing our young. It is tempting to think that similar socially derived learning does not occur for fish. We know, however, through common observation and extensive documentation that learned place-based behavior is common among birds and mammals. There is a vast amount of literature describing the fidelity of individuals, families, and groups to particular territories and migration routes as well as their evolutionary advantages.

Many fish species appear to possess the cognitive capacity for rudimentary social learning and exhibit the social mechanisms necessary for transferring information from older to younger fish. It should not be surprising that recent work suggests that young fish of many species acquire place-based knowledge of migratory routes, spawning sites, and other essential habitats important to their shared life history from older fish (Giske et al. 1998, Huse et al. 2002, Brown and Laland 2003, Rose 2007, De Luca et al. 2014, Takahashi et al. 2014). This kind of place-based learning is apparent even in highly migratory species such as swordfish (Neilson et al. 2007), is well known in salmon, alewife, and cod (Rose 2007), and is present even in low trophic level fish such as herring (McQuinn 1997, Stephenson 1999, Huse 2016). Huse et al. (2002), for example, argue that the social knowledge of overwintering grounds for Norwegian Sea herring was lost in the 1990s because of high fishing pressure on adults, so that recruiting year classes took on new migration patterns, which were then learned by subsequent generations. Consequently, even though fisheries science rarely considers social learning among fish, it seems reasonable that it is frequently found in fish and that the organization of place-based fish communities is a function of this attribute so long as it is present in at least some of the species in the community.

Social learning in fish is important for human-fish interactions because the physical attributes and social behaviors that facilitate learning in fish seem particularly susceptible to human targeting. Older fish (presumably the repository of social knowledge) and aggregations (presumably the setting for the transmission of social memory) are the preferred targets of fishers. Older fish are often the easiest to find, and their high yields generally make them relatively profitable. Consequently, fishers almost always target older fish first, thereby compressing a population's age structure, diminishing its repository of social memory, and changing the patterns of its behavior. The human preference for larger fish is hard to understate. Fish stories are about big fish; pictures of "good fishing" feature big fish.

The few stories and pictures that do not feature big fish emphasize lots of fish. Fishers target aggregations of fish because they also are easy to find and harvest. For example, herring, anchovy, and many other small, low-value forage fish often aggregate in large, easily located schools that are especially vulnerable to large trawls and seines. Anadromous fish conveniently migrate up rivers and streams on their way to spawn and can be caught with inexpensive traps and weirs. Other fish, including most groundfish, aggregate at times and places that make them especially vulnerable, even when their populations are depleted.

In short, older fish and aggregations are the preferred targets of fishing because they are easy to find and profitable; however, within the natural population, older fish are the repository and aggregations are the setting for social learning. Thus, by preferring older fish and aggregations, fishing selectively targets the information that is responsible for much of the self-organizing, especially the place-based dynamics of the natural system. This is not the intended result of fishing, but from the perspective of this theory, it is almost as if fishing were designed to remove the ecological memory necessary for persistent local adaptation.

Collective action: Collective action, that is, social rules or institutions that guide and restrain individual behavior, is a fourth information-economizing mechanism. Socially learned and constructed rules can be thought of as deliberately retained knowledge of collective experience; they are a kind of imperfect collective memory and mental model of what has worked in the past and might work in the future. Collective action lies largely within the province of humans and, if successful, can confer the immense benefits of culture and governance. The collective action question in fisheries is a relatively narrow, particularized version of this broader question of governance, but it illustrates the way 
that costly information constrains the structure and effectiveness of collective action.

The evolution of collective rules in common-pool resources is the subject matter of extensive literature (e.g., Ostrom 1990, North 2005). For the discussion here, however, what is important is that the construction of collective rules is also subject to the inevitable costs of acquiring usable knowledge. These costs lead individuals to focus at the local level, and as a result, the day-to-day decisions they make are at best indifferent and more often unaware of the broader scale effects of their own and their colleagues' actions. This myopia is the direct outcome of each agent's need to minimize uncertainty, but the aggregate effect of all agents acting in this way leads to a system in which there are no self-organizing mechanisms that translate information about the state of the broader system into feedback and selection at the local level. Because of this disconnect, there is no self-organizing basis for conservation. This is the reason for the divergence of individual and social interests, i.e., the "commons dilemma," and why multiscale, designed organization is necessary. This perspective is not radically different from standard bioeconomic theory. However, as I explain later, the information mechanisms driving natural and human interactions generate a system-wide, not a single-species, pattern and require different policies than those employed by standard approaches. These policies are addressed in the Summary.

\section{Hierarchy and scale}

In a self-organizing system, groups occur at multiple scales. They often arrange themselves in loose, nested, hierarchical structures in which the rate of response to change is fastest at lower levels, e.g., quickly responding individual fish within less rapidly changing schools within slower-to-change communities within very slow broad-scale ecosystems (O'Neill et al. 1986). These structures are assembled in variations that differ from place to place and with the passage of seasons. At each scale, many similar but distinct copies of its prototypical unit lodge within numerous locally adapted hierarchies (Low et al. 2002, Norberg et al. 2008). To an outsider, the members of each unit appear the same; to an insider, there are innumerable, clearly important differences.

Significant differences in human and natural system organization Above the scale of the individual, human and natural systems tend to be very different. The human part of the system has powerful and relatively quick-acting, far-from-perfect, collective learning mechanisms that allow the replication and rapid development of successful, order-creating behaviors. Language, culture, and collective action (norms, laws, formal institutions) give humans the ability to retain and transmit knowledge at the level of the group and among groups over a broad spatial extent, allowing the usually imperfect but rapid replication and modification of past successful actions (Boyd and Richardson 2005, Dopfer 2005). Unlike animals, the human response to the depletion of a local environment is not limited to switching prey or moving on to another place. Humans can develop new technologies, modify old ones, create new methods of organizing their activities, find new markets, change their diet, adopt new methods of product preservation, and invent a seemingly neverending array of harvesting innovations.

Each time humans move on, they change the spatial, temporal, and interactive dynamics of the coupled system at a rate that generally far exceeds the rate of adaptation of the natural system. As a result, moving on is a driving force that molds the organization of local systems while it generates a coupled natural and human system dynamic in which the individuals of one major component can largely avoid the near-term consequences of their actions and therefore dominate the fortunes of all others.

Self-organization in the natural system is largely local

The natural system lacks the deliberate collective information mechanisms employed by humans, so its hierarchical structure is much flatter. There is, however, a rapidly growing body of evidence that indicates that some species of fish form localized populations within equally localized communities (for example, Langton et al. 1995, McQuinn 1997, Smedbol and Wroblewski 2002, Knutsen et al. 2003, Kritzer and Sale 2004, Olsen et al. 2005, Conover et al. 2006, Gibb et al. 2007, Fox et al. 2008, Kovach et al. 2010). Among fish, reliable organization occurs among both social and nonsocial learners, but also among individuals that respond largely to very local environmental circumstances, e.g., lobsters, crabs, and bivalves (Incze et al. 2010). The behavioral rules giving rise to both kinds of aggregations tend to be regular and persistent because these rules are retained through inheritance and social learning of individuals. As long as the replication of these rules and the environment in which they were formed is assured, the regularity of that behavior is maintained, e.g., alewife in undisturbed rivers probably school and migrate today much as they did hundreds of years ago. This is not to imply that the conservation of rules leads to constancy of behavior; rather, the idea is that the range of possible behaviors likely had the same scope.

At the scale of the community, however, there is an important qualitative change in the organizational capabilities of the natural system because there is no information mechanism comparable to inheritance or memory. There is no way to record and pass on instructions about how to replicate previous configurations of the community. As a result, regularities observed at the scale of the community and above are simply the shadow of regularities generated by individual activity. For example, the overlapping patterns of place-based migrations, common feeding or wintering grounds, or the nonsocial individual decisions based on suitable habitat depend on the knowledge that fish have of the relative biological or physical constancy of particular places. Even though the community at any particular place may vary dramatically from season to season, its changing components are the result of seasonal changes in place-based decisions by individuals. In combination with seasonal movements, these localized decisions connect different places in the system. For example, the summertime extirpation of a local population of cod will affect other cod who overwinter in the same location but summer at another.

These broader-scale regularities are no more persistent than the local regularities that drive them. They are, in effect, a set of initial conditions that start the energy in the system on a constrained path to entropy. The energy that fish acquire over their lifetime eventually leaves the system, like river water passing through a standing wave; however, before that happens, the genetic and socially learned knowledge acquired by at least some individuals is passed on to younger fish. Thus, when the role of information is considered, individual inheritance and socially based memory 
are the only mechanisms that generate self-organization in the natural system.

\section{Observation and the scale of self-organization}

The absence of broader scale self-organization in natural systems has important implications for human learning about these systems. The more that observation departs from the scale at which inheritance and memory operate, the more extraneous noise and interactions within the system distort signals of system change. For example, if a given year-class of a particular fish species is monitored over a broad range, as is usual with the standard approach, the data collected will reflect changes in the abundance of local components. Some of those components will fare better than others. If the observer considers the population homogeneous and calculates an average change in the abundance, the calculation could only be considered a good indicator of the status of the species if there were some reason to believe that all the components were affected uniformly by the same forces in the system. In a heterogeneous system, this is highly unlikely, rendering the meaning of a calculated broad-scale average ambiguous (Wilson et al. 1999, Wilson 2006, Ying et al. 2011). The strong implication is that meaningful observation has to take place at a local scale where self-organizing mechanisms lead to rapid and tight feedback (Levin 1998). In these circumstances, a human observer might learn when and why a local system is departing from its historically observed patterns. In fact, informed local observations such as this carried out at multiple locations in the broader system might yield a reasonable picture of the state of the broad system and its imminent behavior (Scheffer et al. 2012). This is not to say that the state of the broader system is not important, but rather that a clear understanding of that state has to proceed from multiple local places.

Consider the growing evidence that fishing can extirpate local populations (Ames 1996, La Valley and Feeney 2013, Hayden et al. 2015). When extirpation happens, the organization of natural communities in those places undergoes significant change, but a nonlocal observer who has no knowledge of the history of the place may not discern the significance or even the existence of that change. Ames's (1996) interviews with retired fishers, for example, reveal the loss of many local spawning grounds for cod, haddock, hake, and pollock in the northern part of the Gulf of Maine; this rather substantial change in the ecosystem was unknown to (or ignored by) New England fisheries scientists and managers. In Atlantic Canada, just before the great crash of the northern cod populations, repeated complaints about apparent local extirpations were ignored because they were thought to be unreliable, self-serving reports of local anomalies that were inconsequential at the broader scale that regulators assumed was relevant (McCay and Finlayson 1998).

\section{Diversity}

At each scale in the hierarchy of a living system, there are numerous nearly redundant groups; local adaptations by each group lead to a diverse system environment, e.g., numerous schools of a species of fish, each one of which reflects the unique experiences of its members, or multiple groups of fishers with different histories, or numerous local governments whose rules and administrations depend on their social history and physical environment (Low et al. 2002). In the natural system, groups of each species tend to repeat similar behavioral patterns and participate in similar ecological processes, but modified in ways that reflect the circumstances and seasonality of particular places. This kind of diversity is usually interpreted as an important attribute contributing to the resilience of both natural and social systems (Levin 1998, Gunderson and Holling 2002, Norberg et al. 2008), especially when it is complemented by life histories that feature high fecundity and strongly opportunistic behavior.

When one considers the interactions of humans and the natural system, diversity is important because the behavior of fish has evolved in response to regular threats and opportunities in the natural world. However, behaviors that confer fitness in the natural system are often vulnerabilities when confronted with the rapid pace of human adaptation. Fishers' behavior is carefully calibrated to these vulnerabilities. Any discussion with commercial or recreational fishers, for example, reveals the importance of gear and complementary search techniques. Both are designed to target the most vulnerable behavioral or physical traits of fish. Often, these vulnerable traits are associated with the mechanisms that lead to social learning, perhaps because these otherwise not very vulnerable traits are a relatively safe repository for that learning. For example, extended age structure tends to stabilize a population; it reduces predation among older fish and retains the social memory of place. However, because older, larger fish are easier to find, often less wary of predators, and more profitable, they are selectively targeted. This truncates age structure and weakens the repositories of social learning. Schooling is probably the setting in which most social learning takes place, but it makes fish easier to find and makes their harvest more profitable. Regular migration and fidelity to a spawning time and location is fit behavior until fishers with nets learn where and when spawning takes place.

In short, the competitive dominance of humans stems largely from their ability to exploit aspects of fish behavior that natural predators either cannot do or do less efficiently. The selective targeting that results diminishes the constraining or enabling effect the targeted fish have on the behavior and abundance of their natural prey and predators, reducing the spatial and temporal regularity of all their interactions. These changes in the organization of the natural system realign the patterns of potential fishing opportunities, further reinforcing fishers' incentives to change their targets and move on.

Still another side of diversity concerns the difficulty it creates for human understanding of the natural system. Fishes' behavioral flexibility may be seen as an adaptation to the lack of selforganizing mechanisms above the scale of the individual. The resulting irregularity of the environment at this broader scale subjects fish frequently to surprising contingencies, placing a high evolutionary premium on the ability to respond flexibly. This ability is helpful, or necessary, for fish, but it leads to highly variable, unpredictable interactions within the fish community. This makes it difficult for a human observer to understand the ways that human activity affect the natural system and is the source of considerable scientific uncertainty. The standard model tries to finesse the problem with the single-species stockrecruitment idea, hoping that ecosystem interactions are inconsequential. In contrast, the ideas expressed here emphasize the importance of those interactions and suggest a substantially different way to address the uncertainty problem as discussed in more detail in the Summary. 


\section{MOVING ON: THE HUMAN DYNAMICS THAT CONNECT AND DISORGANIZE THE NATURAL SYSTEM}

Moving on to new technologies, new markets, and newly discovered resources is the normal dynamic of a competitive, capitalist economy (Beinhocker 2007). However, when this normal dynamic is laid over a natural system, it generates regular system-wide patterns that lead to the disorganization of the natural system. For example, in a relatively simple but patchy fishery, patterns generated by unregulated fishing might be close to what one would expect if fishers were acting as optimal foragers (Charnov 1976). That is, as fishing depletes a local patch, fishers have a strong incentive to find new patches. Generally, one or several individuals begin to test areas in which their prior knowledge indicates the likelihood of good targets; when more promising patches are located, they move and they are then followed by others. In this way, humans create new connections between local patches in the natural system.

In a complex, multispecies, and multiplace fishery, the motivations and patterns of fishing might be characterized in a similar way; fishers target various species at particular places and times according to their relative profitability. If at any time, fishers find profits in one location or for any given target species lower than they might expect elsewhere, they shift their effort to another target that is more likely to be lucrative, i.e., they move on. In this way, the mechanisms of moving on generate a multispecies, multiplace portfolio fishing strategy as a competitive outcome within a community of fishers. The fundamental ingredients for this outcome are a patchy natural system; a lack of, or overly broad, regulatory boundaries; flexible markets; and highly adaptive, mobile fishers. See Gillis et al. (1993), Acheson (2003), Gillis (2003), Myers and Worm (2003), Sethi et al. (2010), and Bolster (2012), among others, for interesting documentation of these patterns.

Portfolio fishing generates new connections among parts of the natural system that are not normally connected, producing a selective, biased impact on the organization of the entire natural system. The fate of species A in location X may be tied suddenly to the state of species B in location Y. There are no self-organizing mechanisms that give the natural system the ability to react to these persistent, non-natural disturbances; as a result, these new connections are another way in which fishing disorganizes the natural system. The process of moving on is not a simple instance of elimination of one stock followed by movement to and elimination of the next. The diversity of the natural system means that new, profitable targets are found long before the originally targeted stocks are fully depleted, so local fisheries persist long after their original reduction. In addition, external markets usually supply substitutes for locally scarce fish; this keeps local prices and the incentives to fish lower than they would be otherwise (Crona et al. 2016). Consequently, moving on may relieve some pressure on local stocks, but it does not eliminate local fishing. However, over time the depletions and compressed age structures of more profitable fisheries increase the likelihood of local extirpations, which in turn increase the irregular behavior of local species, local communities, and eventually, the broader system (Steneck 1997, Rose 2007).
The patterns of these new connections are largely determined by fishers' perceptions of profitable search. Groups of fish close to harbors are more heavily exploited than those far away; fish that are easy to find and harvest attract more effort than those that are difficult to find; larger fish are harvested before smaller fish; species that are easy to process and store and that command a good price are fished more intensively than those that are not. Viewed over a long time, the portfolio effect develops at multiple scales like a social-ecological fractal, that is, quickly at the scale of nearby fresh water, intertidal, and estuarine resources, less rapidly in near-shore communities, slowly across large regional off-shore systems, and very slowly in entire ocean basins (Hederstrom 1959, Jackson et al. 2001, Myers and Worm 2003, Sethi et al. 2010, Swartz et al. 2010, Bolster 2012, Hayden et al. 2015). Changes at each scale affect the other scales in the system; changes at the local level affect broader scales, and changes at broader scales affect circumstances at the local level.

This perspective leads to the idea that unregulated fishing affects the organization of the natural system in three stages:

First, initially, fishing preferentially targets older age classes and aggregations of particular species at particular places, leading to compressed age structures, lower average trophic levels, changes in the relative abundance of populations in the local community, and lower profits. Lower profits locally and the promise of higher profits elsewhere lead fishers and fishing communities to move on to other species, smaller age classes, and other places, eventually extending their portfolio across numerous species and places and forcefully altering the connections between local natural communities. At first, there is no loss of the information necessary for self-organization; neither fishes' DNA nor the socially learned knowledge that supports place-based social behavior is impaired because fishers usually move on well before this happens. This does not imply a steady-state or static system, but rather that the evolved information associated with the characteristic range of system states is still present and available to drive self-organization. Furthermore, given the high fecundity of most ocean species, a system that retains the knowledge and mechanisms for self-organization, even if the relative abundance of fished stocks has been altered, has few barriers to rapid renewal and is likely to persist with variations in organization and abundance that lie within its evolutionary experience. The system remains robust and resilient.

Second, however, as fishing reduces the relative abundance of older fish, it alters the previous nearly regular biophysical attributes of the environment and increasingly disrupts the circumstances in which social learning occurs. The likelihood that socially learned placed-based knowledge will be lost increases. Local extirpations of place-based fish begin to occur, leading to persistent changes in community-scale and broader structure. If it were not for the human tendency to move on, local extirpations would remain relatively localized with little system-wide effect. However, when humans move on, they strongly connect otherwise fairly independent local systems, spreading persistent disorganization. Furthermore, the selectivity of fishing is particularly damaging to place-based fish, leading to shifts in abundance that are strongly biased in favor of those species whose fitness is not dependent on socially acquired knowledge of particular places, typically invertebrates. 
Third, local extirpations lend a longer term permanence to disorganization, a form of system overfishing that is far more serious than the single-species depletions contemplated in standard theory. The end game is one in which fishing redistributes the (nearly constant solar) energy in the system, reorganizing it away from the fairly regular, complex patterns of an unfished system toward a less regular, simpler world dominated by less preferred species (Jackson et al. 2001). With no restraints on fishing, the system is likely to devolve to a sustainable state in which the regularity of plankton abundance is accompanied by the occasional eruption of species that are not dependent on welldeveloped system organization, i.e., low trophic level fish and invertebrates. The other side of this same coin is that restoration, or rebuilding, of natural systems has to establish regularity low in the system before higher trophic organization is possible. For example, Ames and Lichter (2013) nicely document the reproductive viability of cod on the local presence of lipid-rich prey. Because local spawning of those prey has been extirpated by overfishing and dams, cod are not able to reproduce.

Viewed in this way, the idea of a sustainable ecosystem as it is conventionally imagined is largely the expression of a human preference for the self-organization typical of an unfished natural system. After all, that structure is one that provided a wide range of nicely profitable opportunities.

\section{THE ORGANIZATION OF COLLECTIVE ACTION}

As humans move on, they generate social circumstances that make their own collective action more difficult. The persistent local social relationships that enable collective action atrophy; a shared interest in the future of the local resource dissolves; knowledge of the history and ecology of local areas declines; and the social structure that enables the creation of effective, enforceable, restraining rules (Ostrom 1990) becomes less likely. The conditions that facilitate moving on are antithetical to the emergence of collective learning and adaptation. Given this human dynamic, the question is: What kinds of policies might alter the circumstances of fishing so that they facilitate effective collective action?

The basic argument to this point is that the self-organization of complex natural and human systems is the emergent outcome of the search by individual fish and humans for simple, low information cost, local niches. For individual agents, the restricted environment of a local niche makes it possible to learn the regularities of the immediate environment and to understand better the likely outcome of their actions. In a long-evolved natural system, myopic decision making by natural agents occurs in an environment in which the broader scale outcomes of individual actions have largely played out. As a result, individual, self-interested actions based on local circumstances alone do not threaten changes in the basic organization of the system. However, for a newly arrived, dominant species such as humans, as argued earlier, similar myopic decisions can lead to substantial disorganization of the natural system.

From a costly information perspective, understanding how such disorganization takes place and developing the kinds of rules that might conserve the organization of the natural system are the basic problems of collective action. At first glance, the systemwide nature of the problem would seem to require the ability to predict potentially very complex ecological interactions. Standard fisheries theory tried to avoid this problem by assuming strong stock-recruitment relationships; this assumption has not been supported by the evidence, and from my perspective, there is no reason to expect those interactions to be predictable. However, a rule-based, information-constrained system suggests an alternative route for collective action that does not depend on the prediction and control of complex interactions. In the following paragraphs, I lay out eight propositions that capture the essence of this alternative approach.

\section{Sustainability requires the conservation of self-organizing information}

A costly information approach strongly argues that sustainable fishing requires conservation of the information in DNA and social memory necessary for the self-organization of the natural system. In particular, this means that we need to:

- Avoid extinction because knowledge contained in DNA cannot be resuscitated;

- Avoid local extirpations because it will likely take a long time (relative to human processes) for the regrowth of the learned social structure required for place-based behavior in the natural system; and

- Maintain evolved population and community characteristics such as extended age structure, schooling, migration, and habitat necessary for replicating the knowledge that generates spatial and temporal regularity in the natural system.

Implicit in these objectives is the idea that it is not possible to manipulate the abundance of fish through quantitative rules such as optimizing quotas or limits on effort. However, they also imply that as long as the basic information infrastructure of the system is maintained, the system will be resilient, and the high fecundity of fish will keep productivity robust. This expectation is distinctly different from the standard management expectation that yields can be sustained at MSY through the active manipulation of spawning stock biomass.

\section{Boundaries are critical}

Consideration of costly information argues for clear fishing boundaries. The absence of spatial boundaries is the prime, policy-relevant enabler of the human tendency to deplete and move on. With no, or very broad, spatial boundaries, a fisher has strong incentive to chase and get the fish before others get them. There is no incentive to conserve at home or elsewhere (Wilson 2006, Steneck and Wilson 2010, Ying et al. 2011). With no limits on the participants in a fishery, the incentives are the same. Programs such as catch shares moderate the race to fish, but in the absence of ecologically meaningful boundaries, broad-scale catch-share programs have little regard for local conditions and continue to create incentives for moving on (Acheson et al. 2015). Boundaries radically change fishing incentives because they close off opportunities elsewhere. Fishers have to worry about the future at home. With boundaries and mobile fish that cross them, there is an initial, local incentive to engage in intercept operations, but if broader scale governance facilitates negotiations among local governance units, fishers' incentives are redirected to find methods of mutual restraint across boundaries (Acheson 2003, Steneck and Wilson 2010). Fishers begin to worry about what the "other guy" is doing to "their" fish. This is a significant change 
in incentives, especially when compared with standard management, which endorses the activities of roving fishers, interpreting their broad-scale moving on as efficient search and nothing more (Acheson et al. 2015).

\section{Boundaries should be approximately congruent with the natural system}

There are no perfect boundaries in complex systems, but some boundaries are likely to yield better feedback than others (Steneck and Wilson 2010). If governance boundaries are drawn so that they have reasonable conformity with local ecological zones, and if there is a stable population of human actors operating within those boundaries, then agents are able to build familiarity through repeated encounters with one another and the local environment. For this reason, the quality of feedback about the effect of human activity improves. Boundaries, in effect, create a simpler environment for the individual agent and, because of this, they reduce uncertainty and facilitate learning and collective action (Ostrom 1990, North 2005). This means that limited licensing programs should be designed to facilitate collective action rather than to limit catch, as is usually the case.

When viewed from the perspective of broad-scale management, collective action low in the system implies: (1) much more intensive and expensive system monitoring and assessment than might reasonably be addressed by a typical national or regional science program, and (2) the need for local governance arrangements that incorporate fishers' current and historical knowledge of local ecological communities. Whether the costs of these undertakings might be worthwhile depends on the expectation of what might be learned and the value of such knowledge.

\section{Complexity limits our usable knowledge}

Expectations about what might be learned depend on the kind of feedback generated by the natural system. Wilson (1998) notes that in a complex system, it is often possible to work backward from any particular aggregate outcome to figure out the chain of events at each juncture that preceded it. However, this is only possible if there is a well-documented history of events. Wilson's (1998) examples are drawn from organismal systems in which the relationships among components are much more limited than one might expect to find in an ecological or social system. Nevertheless, he emphasizes that when working in the opposite direction, i.e., when attempting to predict, even in these simpler circumstances of nearly obligate interactions, it is almost impossible to know the outcome of each contingency much less a series of contingencies and, for that reason, to predict the aggregate outcome of events that occur low in the system.

In principle, it might be possible to monitor the system in enough detail to anticipate each contingency, but in practice, this is immensely impractical. Mayfield (2013:124) highlights the essential randomness of these events: "When sequential processes admit random events, the possible future becomes different every time such an event occurs." O'Neill et al. (1986) and Gould and Woodruff (1990) emphasize essentially the same point with regard to ecosystems, and as Schindler and Hilborn (2015) conclude about the standard broad-scale, single-species approach, the "sufficiently thorough understanding of ecosystems needed to reduce deep uncertainties is probably not achievable, seriously limiting the potential effectiveness of the predict-and-prescribe
approach."In short, we know that these interactions are extremely important to the functioning of the ecosystem. However, a complex systems approach and practical experience strongly suggest that our ability to predict the macro-scale outcomes of our micro-scale interventions is seriously limited.

\section{Self-organizing information keeps the system within its historical bounds}

A rule-based, information-centered approach will not produce an alternative, magical way to predict the outcome of human activity. However, it does suggest that policies that lead to the retention of self-organizing information in the natural system may keep the organization of the system within its historical range. The argument is similar to the point made by O'Neill et al. (1986) about maintaining the constraints in the system. Presumably, over the course of its evolution, a natural system has "explored" a wide range of possible configurations, and in the course of those explorations, it has incorporated that experience in a set of behavioral rules that is held in DNA and socially acquired memory. These rules define the scope of organizational possibilities for the system. Put differently, it is often argued that the state of an ecosystem is a path-dependent function of its history (Gould and Woodruff 1990). From the perspective argued here, the organizing information in the system (inheritance and memory) is the embedded history of the system, a principal source of path dependence, and excepting external events, is likely to dominate the range of its possible future states. In other words, the conjecture is that policies intended to retain the information required for self-organization are not likely to confer the ability to manipulate system outcomes, but are likely to keep the system within its historical, self-organized bounds.

\section{The conservation of information requires qualitative rules}

The goal of conserving organizing information suggests clear management strategies that emphasize relatively simple harvesting rules. The point of these rules is to protect the individual traits and population processes that retain and replicate self-organizing information. My colleagues and I have previously called such rules "parametric" (Acheson and Wilson 1996). Examples are "slot" and other rules intended to maintain a population of older fish; gear and other prohibitions intended to protect social behaviors such as migrations, spawning and prespawning aggregations, and schooling; protected areas; and a variety of other rules whose designs are based on a working knowledge of the observed behavior and life history of natural agents. Additionally, because the information leading to selforganization is adapted to conditions at various scales and places, rules intended to conserve the retained information have to be aligned accordingly. For example, rules that protect inherited attributes such as a tendency to long life might reasonably be expected to span the entire spatial range of the species. In contrast, rules that affect place-based learned behavior are only effective if carefully designed to reflect conditions at the place where that behavior occurs, e.g., a rule to prevent harvesting of anadromous fish at a particular choke point in a river. Rather than emphasizing uniform rules to control fishing over the extent of the population, the goal of conserving regularizing information implies a variety of scale- and place-appropriate rules that maintain social learning and other self-organizing behaviors in fish. 


\section{Qualitative rules lead to faster learning}

Information-conserving rules are likely to be easier for fishers and managers to learn and refine. They are what fishers would call "common sense." In places where traditional collective action appears to have worked well, these kinds of rules are the usual method of restraint (Schlager and Ostrom 1992, Acheson and Wilson 1996). They are based on relatively persistent attributes of each species or community; they address aspects of the resource that are relatively easy to study with the standard methods of marine ecology, and they bear a strong correspondence with observable reality because their design reflects those aspects of fish behavior that fishers regularly observe and know fairly well. For example, a rule setting a minimum or maximum size of capture applied uniformly over time should have clearly expected effects on the age distribution of the targeted population. Such a rule exerts a continuous influence on the organization of the population and the system; this makes its signal much easier to detect than say a quantitative rule whose signal varies substantially according to the state of the system. Informationconserving rules must pass a persistent filter based on user experience and basic ecology. Furthermore, informationconserving rules employed in the context of a strong and durable social foundation and appropriate user rights lend themselves to individual and group learning because these conditions facilitate the collection of user feedback (Ostrom 1990, Ames 2010). Consequently, when combined with strong local governance, information-conserving rules can be relatively cheap to employ and can be enforceable at sea, on the wharf, and in markets at a reasonable cost.

Nevertheless, localized information-conserving rules are imperfect in two important ways. First, even though local systems are simpler than broader scale systems, they still exhibit complex interactions that make the effect of particular rules difficult to interpret. Additionally, they are not closed systems, so changes outside the system may have important local effects. Rules that are well designed from the local perspective may be confounded by actions taken elsewhere; for example, heavy fishing on a migratory prey species elsewhere may defeat the effect of local rules that might otherwise effectively conserve that species or its predators. Second, as discussed earlier, even very good local feedback does not inform agents about the broader scale effects of their collective action. Thus, local feedback alone stands a good chance of not implementing effective conserving rules or identifying the broad-scale consequences of human activity. These are significant weaknesses that diminish the ability to learn and to implement effective collective action. However, both weaknesses can be addressed with broader scale information.

\section{Effective science and governance require multiple scales with a local emphasis}

At a broad scale, it is possible to think about two different kinds of feedback. One is an averaged value observed at a broad scale, i.e., the kind of information generated by the typical standard assessment. In a complex system, this kind of feedback is slow and ambiguous and has not proven to be very useful (Longhurst 2010). The other kind of broad-scale feedback arises from the comparison of the feedback acquired at different localities. In other words, a significant weakness when trying to learn only at a local level arises from the inability to distinguish local variability due to natural and external events from variability due to local human action. Comparisons across localities do not guarantee a solution to this problem, but they do add significant helpful information. For example, even when a broad-scale event such as climate change seems to affect a fishery, the only way to sort out changes due to this broad-scale event from other possible causes such as fishing is to look at the differences, or the absence of differences, between localities. This is the usual immediate and appropriate response of most scientists and others. However, when a science program such as implemented by the standard model assumes broad-scale uniformity, it forfeits the ability to observe and make sense of these patterns. In this kind of singlescale approach, change sneaks up without warning; systems seem simply to collapse or flip, and little more can be said (Scheffer et al. 2012). Unfortunately, our scientific systems in the ocean are often organized with little systematic data collection at the local level except for a few physical variables at convenient locations, e.g., temperature, salinity, wind, and waves from remote sensing buoys.

Reorganizing the ocean science program so that it is better able to obtain feedback is not likely to occur without substantial changes in the scale of governance and in the design of rights accorded fishers. The reasons for local governance have been carefully elaborated in the literature following Ostrom's (1990) work. Briefly summarized: effective governance requires clear boundaries that are aligned as closely as possible with the natural system; users must have clearly defined rights consistent with the boundaries of the governance unit; users have to have the ability to participate in the construction of harvesting rules and in their monitoring, sanctioning, and enforcement; and broader scale governance needs to support and also constrain local governance. These are fundamental requirements for effective governance in a complex adaptive system. If they are not met, collective feedback, learning, and the ability to sustain complex resources will be significantly impaired.

\section{SUMMARY}

My fundamental argument is that the self-organization of living systems is the emergent product of the information natural and human agents retain in their DNA and memory. The acquisition of that information, especially the information held in memory, occurs in ways that are shaped largely by the costs of the information agents need to resolve uncertainty. These costs lead agents to prefer simple associations with other familiar agents and surroundings. Familiarity is advantageous to agents because it places them in circumstances in which they are better able to learn by experience and to make choices that refine their inherited capabilities. When all agents act in this way, they tend to organize with other familiar agents into locally adapted groups; groups reinforce the advantages of familiarity and lead to persistent patterns of association and a self-organized system.

The conjecture presented here is that fishing impairs the selforganizing information in the natural system. The activities of fishers are highly responsive to the costs of information. These costs lead fishers to target fish for which search costs are low relative to their value, leading to a preference for older fish and fish that aggregate. This kind of selectivity is strongly biased toward the removal of fish with place-based knowledge and leads to local depletions as fishing intensifies, and then extirpations. This begins to erode the fabric of the entire system, beginning at 
the local level. Fishers respond to local depletions by moving on to other species and places, extending the erosion more, and then repeating the pattern in place after place, for species after species, eventually disorganizing the system and diminishing their own opportunities.

Fishers behave in this manner because the complexity of system interactions yields no signals that clearly connect individual actions with broad-scale, collective outcomes. The feedback fishers receive and the selection pressures they experience are localized. Consequently, it is difficult for fishers, scientists, and managers to understand the broader scale outcome of local actions. Standard theory hoped, vainly it turns out, that a strong functional relationship between spawning stock size and subsequent recruitment would provide the basis for prediction and control without having to understand the complex interactions within the ecosystem.

A costly information perspective does not suggest that the prediction of complex interactions is feasible. Rather, it argues that the organizing information in the natural system, i.e., DNA and socially derived memory, constrains the probable states the system might assume and that policies designed to preserve this information are likely to keep the organization of the system within its historical bounds. Consequently, the paramount collective action problem is learning the kinds of fishing rules that might preserve the retained information that drives selforganization in the natural system.

This learning problem is itself an organizational problem. Collective learning depends on the acquisition of timely and accurate feedback; in fisheries, feedback is most direct at local levels in the natural system, where retained information gives rise to regular patterns and organization. Even at a broad scale, the most useful feedback is likely to be found in comparisons of local systems. This means that effective collective learning and adaptation in a complex adaptive system requires: (1) organizational boundaries that are aligned as nearly as possible with the organization of the natural system; (2) a local scientific focus with the active participation of users in the observation, collection, and interpretation of data; and (3) an emphasis on the retention of the information required for the self-organization of the natural system through the use of rules about how, when, and where fish are caught.

Responses to this article can be read online at: http://www.ecologyandsociety.org/issues/responses. $\mathrm{php} / 9356$

\section{Acknowledgments:}

This paper is my interpretation of a decades-long discussion with colleagues and friends, especially Jim Acheson, Ted Ames, Bob Steneck, Yong Chen, Robin Alden, and Spencer Apollonio; with the always skeptical biologists in my family, Karen Wilson, Theo Willis, and Carl Wilson; and with numerous Maine fishers and neighbors. Their patience is remarkable. Recent discussions with Bill Leavenworth, Karen Alexander, Josh Stoll, Mattie Rodrigue, Bruce Bourque, and other members of the Fresh and Saltwater Workshop have been very helpful. Karen Alexander and Barbara Harrity contributed two thorough and insightful editings. Finally, Heather Leslie, Jarl Giske, Charles Lucas, Carl Simon, Bobbi Low, and two anonymous reviewers helpfully and constructively challenged the basic ideas in the paper in ways that improved it greatly. Funding from Robert McNeil and the Islesboro Island Trust, Maine Sea Grant, and the National Science Foundation Program in the Dynamics of Coupled Natural and Human Systems (Project 0909449) has been essential and thoroughly appreciated. Longterm foundational support was provided by the USDA National Institute of Food and Agriculture, project number \#ME0-021412 through the Maine Agricultural and Forest Experiment Station (MAFES publication 3535).

\section{LITERATURE CITED}

Acheson, J. M. 2003. Capturing the commons: devising institutions to manage the Maine lobster industry. University Press of New England, Lebanon, New Hampshire, USA.

Acheson, J., S. Apollonio, and J. Wilson. 2015. Individual transferable quotas and conservation: a critical assessment. Ecology and Society 20(4):7. http://dx.doi.org/10.5751/ES-07912-200407

Acheson, J., and J. Wilson. 1996. Order out of chaos: the case for parametric fisheries management. American Anthropologist 98 (3):579-594. http://dx.doi.org/10.1525/aa.1996.98.3.02a00110

Akerlof, G. A. 1970. The market for "lemons": quality uncertainty and the market mechanism. Quarterly Journal of Economics 84 (3):488-500. https://doi.org/10.2307/1879431

Ames, E. P. 1996. Cod and haddock spawning grounds in the Gulf of Maine: from Grand Manan Channel to Ipswich Bay. Island Institute, Rockland, Maine, USA.

Ames, E. P. 2004. Atlantic cod stock structure in the Gulf of Maine. Fisheries 29(1):10-28. http://dx.doi.org/10.1577/1548-8446 (2004)29[10:acssit]2.0.co:2

Ames, E. P., and J. Lichter. 2013. Gadids and alewives: structure within complexity in the Gulf of Maine. Fisheries Research 141:70-78. http://dx.doi.org/10.1016/j.fishres.2012.09.011

Ames, T. 2010. Multispecies coastal shelf recovery plan: a collaborative, ecosystem-based approach. Marine and Coastal Fisheries 2(1):217-231. http://dx.doi.org/10.1577/c09-052.1

Andersen, B. S., C. Jørgensen, S. Eliassen, and J. Giske. 2015. The proximate architecture for decision-making in fish. Fish and Fisheries 17(3):680-695. http://dx.doi.org/10.1111/faf.12139

Arrow, K. J. 1962. The economic implications of learning by doing. Review of Economic Studies 29(3):155-173. [online] URL: http://www.jstor.org/stable/2295952

Barnes, M. L., S. Arita, K. Kalberg, and P. Leung. 2017. When does it pay to cooperate? Strategic information exchange in the harvest of common-pool fishery resources. Ecological Economics 131:1-11. http://dx.doi.org/10.1016/j.ecolecon.2016.08.005

Beinhocker, E. D. 2007. The origin of wealth: the radical remaking of economics and what it means for business and society. Harvard Business School Press, Boston, Massachusetts, USA.

Beverton, R. 1998. Fish, fact and fantasy: a long view. Reviews in Fish Biology and Fisheries 8(3):229-249. http://dx.doi. org/10.1023/A:1008888411100 
Beverton, R. J. H., and S. J. Holt. 1957. On the dynamics of exploited fish populations. Great Britain Ministry of Agriculture, Fisheries and Food, fisheries investigations series 2, volume 19. H. M. Stationery Office, London, UK.

Bolster, W. J. 2012. The mortal sea: fishing the Atlantic in the age of sail. Harvard University Press, Cambridge, Massachusetts, USA. http://dx.doi.org/10.4159/harvard.9780674067219

Boyd, R., and P. J. Richerson. 2005. The origin and evolution of cultures. Oxford University Press, Oxford, UK.

Brown, C., and K. N. Laland. 2003. Social learning in fishes: a review. Fish and Fisheries 4(3):280-288. http://dx.doi.org/10.1046/ j.1467-2979.2003.00122.x

Charles, A. T. 2001. Sustainable fishery systems. Blackwell, Malden, Massachusetts, USA. http://dx.doi.org/10.1002/9780470698785

Charnov, E. L. 1976. Optimal foraging, the marginal value theorem. Theoretical Population Biology 9(2):129-136. http://dx. doi.org/10.1016/0040-5809(76)90040-X

Christy, F. T. Jr. 1982. Territorial use rights in marine fisheries: definitions and conditions. FAO Fisheries Technical Paper 227. Food and Agriculture Organization, Rome, Italy. [online] URL: http://www.fao.org/docrep/003/T0507E/T0507E00.HTM

Coase, R. 1937. The nature of the firm. Economica, New Series 4(16):386-405.

Conover, D. O., L. M. Clarke, S. B. Munch, and G. N. Wagner. 2006. Spatial and temporal scales of adaptive divergence in marine fishes and the implications for conservation. Journal of Fish Biology 69:21-47. http://dx.doi.org/10.1111/j.1095-8649.2006.01274. $\underline{\mathrm{x}}$

Crona, B. I., T. M. Daw, W. Swartz, A. V. Norström, M. Nyström, M. Thyresson, C. Folke, J. Hentati-Sundberg, H. Österblom, L. Deutsch, and M. Troell. 2016. Masked, diluted and drowned out: how global seafood trade weakens signals from marine ecosystems. Fish and Fisheries 17(4):1175-1182. http://dx.doi. org/10.1111/faf.12109

De Luca, G., P. Mariani, B. R. MacKenzie, and M. Marsili. 2014. Fishing out collective memory of migratory schools. Journal of the Royal Society: Interface 11(95). http://dx.doi.org/10.1098/ $\underline{\text { rsif. } 2014.0043}$

Dopfer, K. 2005. Evolutionary economics: a theoretical framework. Pages 3-59 in K. Dopfer, editor. The evolutionary foundations of economics. Cambridge University Press, Cambridge, UK.

Finley, C. 2011. All the fish in the sea: maximum sustainable yield and the failure of fisheries management. University of Chicago Press, Chicago, Illinois, USA. http://dx.doi.org/10.7208/ chicago/9780226249681.001.0001

Fox, C. J., M. Taylor, M. Dickey-Collas, P. Fossum, G. Kraus, N. Rohlf, P. Munk, C. J. G. van Damme, L. J. Bolle, D. L. Maxwell, and P. J. Wright. 2008. Mapping the spawning grounds of North Sea cod (Gadus morhua) by direct and indirect means. Proceedings of the Royal Society B 275(1642):1543-1548. http://dx.doi. org/10.1098/rspb.2008.0201
Gibb, F. M., I. M. Gibb, and P. J. Wright. 2007. Isolation of Atlantic cod (Gadus morhua) nursery areas. Marine Biology 151 (3):1185-1194. http://dx.doi.org/10.1007/s00227-006-0565-0

Gillis, D. M. 2003. Ideal free distributions in fleet dynamics: a behavioral perspective on vessel movement in fisheries analysis. Canadian Journal of Zoology 81(2):177-187. http://dx.doi. org/10.1139/z02-240

Gillis, D. M., R. M. Peterman, and A. V. Tyler. 1993. Movement dynamics in a fishery: application of the ideal free distribution to spatial allocation of effort. Canadian Journal of Fisheries and Aquatic Sciences 50(2):323-333. http://dx.doi.org/10.1139/ 993-038

Giske, J., S. Eliassen, Ø. Fiksen, P. J. Jakobsen, D. L. Aksnes, C. Jørgensen, and M. Mangel. 2013. Effects of the emotion system on adaptive behavior. American Naturalist 182(6):689-703. http:// dx.doi.org/10.1086/673533

Giske, J., G. Huse, and Ø. Fiksen. 1998. Modelling spatial dynamics of fish. Reviews in Fish Biology and Fisheries 8(1):57-91. http://dx.doi.org/10.1023/A:1008864517488

Gordon, S. 1954. The economic theory of a common-property resource: the fishery. Journal of Political Economy 62(2):124-142.

Gould, S. J., and D. S. Woodruff. 1990. History as a cause of area effects: an illustration from Cerion on Great Inagua, Bahamas. Biological Journal of the Linnean Society 40(1):67-98. http://dx. doi.org/10.1111/j.1095-8312.1990.tb00535.x

Granovetter, M. S. 1973. The strength of weak ties. American Journal of Sociology 78(6):1360-1380. https://doi.org/10.1086/225469

Gunderson, L., and C. Holling. 2002. Panarchy: understanding transformations in human and natural systems. Island Press, Washington, D.C., USA.

Hayden, A., J. Acheson, M. Kersula, and J. Wilson. 2015. Spatial and temporal patterns in the cod fisheries of the North Atlantic. Conservation and Society 13(4):414-425. http://dx.doi. org/10.4103/0972-4923.179878

Hayek, F. 1945. The use of knowledge in society. American Economic Review 35(4):519-530.

Hederstrom, H. 1959. Observations on the age of fishes. Report/ Institute of Freshwater Research Drottningholm 40:161-164.

Holland, J. H. 1975. Adaptation in natural and artificial systems: an introductory analysis with applications to biology, control, and artificial intelligence. University of Michigan Press, Ann Arbor, Michigan, USA.

Holland, J. H. 2012. Signals and boundaries: building blocks for complex adaptive systems. MIT Press, Cambridge, Massachusetts, USA.

Holland, J. H. 2014. Complexity: a very short introduction. Oxford University Press, New York, USA. http://dx.doi.org/10.1093/ actrade/9780199662548.001.0001

Huse, G. 2016. A spatial approach to understanding herring population dynamics. Canadian Journal of Fisheries and Aquatic Sciences 73(2):177-188. http://dx.doi.org/10.1139/cjfas-2015-0095 
Huse, G., S. Railsback, and A. Feronö. 2002. Modelling changes in migration pattern of herring: collective behaviour and numerical domination. Journal of Fish Biology 60(3):571-582. http://dx.doi.org/10.1111/j.1095-8649.2002.tb01685.x

Incze, L., H. Xue, N. Wolff, D. Xu, C. Wilson, R. Steneck, R. Wahle, P. Lawton, N. Pettigrew, and Y. Chen. 2010. Connectivity of lobster (Homarus americanus) populations in the coastal Gulf of Maine: part II. Coupled biophysical dynamics. Fisheries and Oceanography 19(1):1-20. http://dx.doi.org/10.1111/ j.1365-2419.2009.00522.x

Jackson, J. B. C., M. X. Kirby, W. H. Berger, K. A. Bjorndal, L. W. Botsford, B. J. Bourque, R. H. Bradbury, R. Cooke, J. Erlandson, J. A. Estes, T. P. Hughes, S. Kidwell, C. B. Lange, H. S. Lenihan, J. M. Pandolfi, C. H. Peterson, R. S. Steneck, M. J. Tegner, and R. R. Warner. 2001. Historical overfishing and the recent collapse of coastal ecosystems. Science 293(5530):629-637. http://dx.doi.org/10.1126/science.1059199

Knight, F. H. 1921. Risk, uncertainty, and profit. Houghton Miflin, Boston, Massachusetts, USA.

Knutsen, H., P. E. Jorde, C. André, and N. C. H. R. Stenseth. 2003. Fine-scaled geographical population structuring in a highly mobile marine species: the Atlantic cod. Molecular Ecology 12 (2):385-394. http://dx.doi.org/10.1046/j.1365-294x.2003.01750.x

Kovach, A. I., T. S. Breton, D. L. Berlinsky, L. Maceda, and I. Wirgin. 2010. Fine-scale spatial and temporal genetic structure of Atlantic cod off the Atlantic coast of the USA. Marine Ecology Progress Series 410:177-195. http://dx.doi.org/10.3354/meps08612

Kritzer, J. P., and P. F. Sale. 2004. Metapopulation ecology in the sea: from Levins' model to marine ecology and fisheries science. Fish and Fisheries 5(2):131-140. http://dx.doi.org/10.1111/ j.1467-2979.2004.00131.X

Langton, R. W., P. J. Auster, and D. C. Schneider. 1995. A spatial and temporal perspective on research and management of groundfish in the northwest Atlantic. Reviews in Fisheries Science 3(3):201-229. http://dx.doi.org/10.1080/10641269509388572

La Valley, K. J., and R. G. Feeney. 2013. Reconciling spatial scales and stock structures for fisheries science and management. Fisheries Research 141:1-2. http://dx.doi.org/10.1016/j.fishres.2013.02.014

Levin, S. A. 1998. Ecosystems and the biosphere as complex adaptive systems. Ecosystems 1(5):431-436. http://dx.doi. org/10.1007/s100219900037

Levin, S. A., and J. Lubchenco. 2008. Resilience, robustness, and marine ecosystem-based management. BioScience 58(1):27-32. https://doi.org/10.1641/B580107

Levin, S., T. Xepapadeas, A.-S. Crepin, J. Norberg, A. de Zeeuw, C. Folke, T. Hughes, K. Arrow, S. Barrett, G. Daily, P. Ehrlich, N. Kautsky, K.-G. Mäler, S. Polasky, M. Troell, J. R. Vincent, and B. Walker. 2013. Social-ecological systems as complex adaptive systems: modeling and policy implications. Environment and Development Economics 18(2):111-132. http://dx.doi.org/10.1017/ $\underline{\mathrm{s} 1355770 \mathrm{x} 12000460}$

Longhurst, A. 2010. Mismanagement of marine fisheries. Cambridge University Press, Cambridge, UK. https://doi. org/10.1017/cbo9781139195928
Low, B., E. Ostrom, C. Simon, and J. Wilson. 2002. Redundancy and diversity: do they influence optimal management? Pages 83-114 in F. Berkes, J. Colding, and C. Folke, editors. Linking social and ecological systems. Cambridge University Press, Cambridge, UK. https://doi.org/10.1017/CBO9780511541957.007

Maxwell, J. C. 2001. Theory of heat. Dover, Mineola, New York, USA.

Mayfield, J. E. 2013. The engine of complexity: evolution as computation. Columbia University Press, New York, New York, USA.

McCay, B. 2002. Emergence of institutions for the commons: contexts, situations, and events. Pages 361-402 in E. Ostrom, T. Dietz, N. Dolsak, P. C. Stern, S. Stonich, and E. U. Weber, editors. The drama of the commons. National Academies Press, Washington, D.C., USA. [online] URL: https://doi.org/10.17226/10287

McCay, B., and C. Finlayson. 1998. Crossing the threshold of system resilience: the commercial extinction of northern cod. Pages 311-338 in F. Berkes and C. Folke, editors. Linking social and ecological systems: institutional learning for resilience. Beijer International Institute of Ecological Economics, Royal Swedish Academy of Sciences, Stockholm, Sweden.

McLeod, K., and H. Leslie, editors. 2009. Ecosystem-based management for the oceans. Island Press, Washington, D.C., USA.

McQuinn, I. H. 1997. Metapopulations and the Atlantic herring. Reviews in Fish Biology and Fisheries 7(3):297-329. http://dx.doi. org/10.1023/A:1018491828875

Mitchell, M. 2009. Complexity: a guided tour. Kindle edition. Oxford University Press, Oxford, UK.

Myers, R. A., and B. Worm. 2003. Rapid worldwide depletion of predatory fish communities. Nature 423:280-283. http://dx.doi. org/10.1038/nature 01610

Neilson, J. D., S. D. Paul, and S. C. Smith. 2007. Stock structure of swordfish (Xiphias gladius) in the Atlantic: a review of the nongenetic evidence. Collective Volume of Scientific Papers ICCAT 61:25-60. [online] URL: https://www.iccat.int/Documents/CVSP/ CV061 2007/no 1/CV061010025.pdf

Norberg, J., J. Wilson, B. Walker, and E. Ostrom. 2008. Diversity and resilience of social-ecological systems. Pages 46-80 in J. Norberg and G. S. Cumming, editors. Complexity theory for a sustainable future. Columbia University Press, New York, New York, USA.

North, D. C. 2005. Understanding the process of economic change. Princeton University Press, Princeton, New Jersey, USA. http:// dx.doi.org/10.1515/9781400829484

O’Neill, R. V., D. L. DeAngelis, J. B. Waide, and T. F. H. Allen. 1986. A hierarchical concept of ecosystems. Princeton University Press, Princeton, New Jersey, USA.

Olsen, E. M., G. R. Lilly, M. Heino, M. J. Morgan, J. Brattey, and U. Dieckemann. 2005. Assessing changes in age and size at maturation in collapsing populations of Atlantic cod (Gadus morhua). Canadian Journal of Fisheries and Aquatic Sciences 62 (4):811-823. http://dx.doi.org/10.1139/f05-065 
Ostrom, E. 1990. Governing the commons: the evolution of institutions for collective action. Cambridge University Press, Cambridge, UK.

Ostrom, E. 2000. Collective action and the evolution of social norms. Journal of Economic Perspectives 14(3):137-158. http://dx. doi.org/10.1257/jep.14.3.137

Pauly, D., V. Christensen, J. Dalsgaard, R. Froese, and F. Torres Jr. 1998. Fishing down marine food webs. Science 279 (5352):860-863. http://dx.doi.org/10.1126/science.279.5352.860

Pikitch, E. K., C. Santora, E. A. Babcock, A. Bakun, R. Bonfil, D. O. Conover, P. Dayton, P. Doukakis, D. Fluharty, B. Heneman, E. D. Houde, J. Link, P. A. Livingston, M. Mangel, M. K. McAllister, J. Pope, and K. J. Sainsbury. 2004. Ecosystem-based fishery management. Science 305:346-347. http://dx.doi. org/10.1126/science.1098222

Ricker, W. E. 1954. Stock and recruitment. Journal of the Fisheries Research Board of Canada 11(5):559-623. http://dx.doi. org/10.1139/f54-039

Rose, G. A. 2005. On distributional responses of North Atlantic fish to climate change. ICES Journal of Marine Science 62 (7):1360-1374. http://dx.doi.org/10.1016/j.icesjms.2005.05.007

Rose, G. A. 2007. Cod: the ecological history of the North Atlantic fisheries. Breakwater, St. John's, Canada.

Scheffer, M., S. R. Carpenter, T. M. Lenton, J. Bascompte, W. Brock, V. Dakos, J. van de Koppel, I. A. van de Leemput, S. A. Levin, E. H. van Nes, M. Pascual, and J. Vandermeer. 2012. Anticipating critical transitions. Science 338:344-348. https://doi. org/10.1126/science. 1225244

Schindler, D. E., and R. Hilborn. 2015. Prediction, precaution, and policy under global change. Science 347(6225):953-954. http://dx.doi.org/10.1126/science.1261824

Schlager, E., and E. Ostrom. 1992. Property-rights regimes and natural resources: a conceptual analysis. Land Economics 68 (3):249-262. [online] URL: http://www.jstor.org/stable/3146375

Sethi, S. A., T. A. Branch, and R. Watson. 2010. Global fishery development patterns are driven by profit but not trophic level. Proceedings of the National Academy of Sciences 107 (27):12163-12167. http://dx.doi.org/10.1073/pnas.1003236107

Simon, H. A. 1962. The architecture of complexity. Proceedings of the American Philosophical Society 106(6):467-482. [online] URL: http://www.jstor.org/stable/985254

Simon, H. A. 2002. Near decomposability and the speed of evolution. Industrial and Corporate Change 11(3):587-599. http:// dx.doi.org/10.1093/icc/11.3.587

Smedbol, R. K., and J. S. Wroblewski. 2002. Metapopulation theory and northern cod population structure: interdependency of subpopulations in recovery of a grounfish population. Fisheries Research 55(1-3):161-174. http://dx.doi.org/10.1016/ S0165-7836(01)00289-2

Steneck, R. 1997. Fisheries-induced biological changes to the structure and function of the Gulf of Maine Ecosystem. Pages 153-167 in G. T. Wallace and E. F. Braasch, editors. Proceedings of the Gulf of Maine Ecosystem Dynamics: a scientific symposium and workshop. Regional Association for Research on the Gulf of Maine, Massachusetts, USA.

Steneck, R. S., and J. A. Wilson. 2010. A fisheries play in an ecosystem theater: challenges of managing ecological and social drivers of marine fisheries at multiple spatial scales. Bulletin of Marine Science 86(2):387-411.

Stephenson, R. L. 1999. Stock complexity in fisheries management: a perspective of emerging issues related to population sub-units. Fisheries Research 43(1-3):247-249. http:// dx.doi.org/10.1016/S0165-7836(99)00076-4

Swartz, W., E. Sala, S. Tracey, R. Watson, and D. Pauly. 2010. The spatial expansion and ecological footprint of fisheries (1950 to present). Plos One 5(12):e15143. https://doi.org/10.1371/ journal.pone.0015143

Takahashi, K., R. Masuda, and Y. Yamashita. 2014. Development of observational learning during school formation in jack mackerel Trachurus japonicus juveniles. Behavioural Processes 103:52-57. http://dx.doi.org/10.1016/j.beproc.2013.10.012

Thompson, D. 2017. The four letter code to selling just about anything. The Atlantic January/February. [online] URL: https:// www.theatlantic.com/magazine/archive/2017/01/what-makes-things$\underline{\mathrm{cool} / 508772 /}$

Ulltang, Ø. 1998. Explanations and predictions in fisheries science - problems and challenges in a historical and epistemological perspective. Fisheries Research 37(1-3):297-310. http://dx.doi.org/10.1016/s0165-7836(98)00145-3

Urbanowicz, R. J., and J. H. Moore. 2009. Learning classifier systems: a complete introduction, review, and roadmap. Journal of Artificial Evolution and Applications 2009:736398. http://dx. doi.org/10.1155/2009/736398

Watts, D. J. 2003. Small worlds: the dynamics of networks between order and randomness. Princeton University Press, Princeton, New Jersey, USA.

Weaver, W. 1948. Science and complexity. American Scientist 36 (4):536-544.

Williamson, O. E. 1975. Markets and hierarchies: analysis and antitrust implications. Free Press, New York, New York, USA.

Wilson, E. O. 1998. Consilience: the unity of knowledge. Alfred A. Knopf, New York, New York, USA.

Wilson, J. A. 1990. Fishing for knowledge. Land Economics 66 (1):12-29. http://dx.doi.org/10.2307/3146679

Wilson, J. A. 2006. Matching social and ecological systems in complex ocean fisheries. Ecology and Society 11(1):9. http://dx. doi.org/10.5751/es-01628-110109

Wilson, J. A., J. M. Acheson, and T. R. Johnson. 2013a. The cost of useful knowledge and collective action in three fisheries. Ecological Economics 96:165-172. https://doi.org/10.1016/j. ecolecon.2013.09.012

Wilson, J., J. Hill, M. Kersula, C. L. Wilson, L. Whitsel, L. Yan, J. Acheson, Y. Chen, C. Cleaver, C. Congdon, A. Hayden, P. Hayes, T. Johnson, G. Morehead, R. Steneck, R. Turner, R. Vadas, and C. J. Wilson. 2013b. Costly information and the evolution of 
self-organization in a small, complex economy. Journal of Economic Behavior and Organization 90(S):S76-S93. http://dx. doi.org/10.1016/j.jebo.2012.12.019

Wilson, J., B. Low, R. Costanza, and E. Ostrom. 1999. Scale misperceptions and the spatial dynamics of a social-ecological system. Ecological Economics 31(2):243-257. http://dx.doi. org/10.1016/S0921-8009(99)00082-8

Xie, K., G. E. Fox, J. Liu, C. Lyu, J. C. Lee, H. Kuang, S. Jacobs, M. Li, T. Liu, S. Song, and J. Z. Tsien. 2016. Brain computation is organized via power-of-two-based permutation logic. Frontiers in Systems Neuroscience 10. http://dx.doi.org/10.3389/fnsys.2016.00095

Ying, Y., Y. Chen, L. Lin, and T. Gao. 2011. Risks of ignoring fish population spatial structure in fisheries management. Canadian Journal of Fisheries and Aquatic Sciences 68 (12):2101-2120. http://dx.doi.org/10.1139/f2011-116 